\title{
Effect of Ethanolic Extract of Propolis on Serum Biochemical Factors Level and Total Antioxidant Capacity in Adult Male Rats
}

\author{
Gheybi N. ${ }^{1}$ PhD, Bakhshi Biniyaz R. ${ }^{2}$ BSc, Taherkhani R. ${ }^{2}$ BSc, Jahani Hashemi H. ${ }^{3}$ PhD, Chegini R. ${ }^{4} B S c$, \\ Saremi M.4 BSc, Azhdari Zarmehri H. ${ }^{5}$ PhD, Najafipour R. ${ }^{6}$ PhD, Sofiabadi M.* PhD
}

\begin{abstract}
*Physiology Department, Medicine Faculty, Qazvin University of Medical Sciences, Qazvin, Iran ${ }^{1}$ Biomedical Technology Incubator Department, Paramedical School, Qazvin University of Medical Sciences, Qazvin, Iran

${ }^{2}$ Laboratory Sciences Department, Paramedical School, Qazvin University of Medical Sciences, Qazvin, Iran ${ }^{3}$ Biostatics \& Social Health Department, Medicine Faculty, Qazvin University of Medical Sciences, Qazvin, Iran ${ }^{4}$ Surgeon Technology Sciences Department, Paramedical School, Qazvin University of Medical Sciences, Qazvin, Iran

5Physiology Department, Medicine Faculty, Torbat Haydarieh University of Medical Sciences, Torbat Haydarieh, Iran

${ }^{6}$ Biochemistry \& Genetic Department, Medicine Faculty, Qazvin University of Medical Sciences, Qazvin, Iran
\end{abstract}

\begin{abstract}
Aims: Propolis is one of the natural materials collected by the honeybees. The material is extensively used to treat some diseases. The aim of this study was to determine the effects of ethanol extract of propolis of Qazvin plain on some biochemical factors, as well as serum antioxidant capacity, in adult male Wistar rats.

Materials \& Methods: In the experimental study, 40 adult male Wistar rats were divided into four groups ( $\mathrm{n}=10$ per group). The first was control group. The experimental groups received 50,100 , and $200 \mathrm{mg} / \mathrm{kg}$ propolis. After $10-$ day gavage, the serum of the rats being extracted, glucose, triglyceride, aspartate aminotransferase, alanine aminotransferase, and total antioxidant capacity were measured. Data was analyzed by SPSS 20 software using one-way ANOVA and Tykey's post-hoc tests.

Findings: There was no significant difference in the blood sugar level between different groups and control group. There was a significant reduction in triglyceride level in "100mg/kg" group than control group $(\mathrm{p}<0.001)$. There was a significant increase in aspartate aminotransferase level in "100mg/kg" $(\mathrm{p}<0.01)$ and "200mg/kg" ( $\mathrm{p}<0.001)$ groups. There was a significant reduction in alanine aminotransferase level in " $50 \mathrm{mg} / \mathrm{kg}$ " group $(\mathrm{p}<0.001)$. Propolis led to a significant increase in the total antioxidant capacity of serum, especially at $50 \mathrm{mg} / \mathrm{kg}(\mathrm{p}<0.05)$ and $100 \mathrm{mg} / \mathrm{kg}(\mathrm{p}<0.01)$ doses.

Conclusion: Oral consumption of propolis has a moderating effect on some blood biochemical factors especially triglyceride. In addition, it increases serum total antioxidant capacity. Nevertheless, its excessive consumption might damage patients with liver diseases.
\end{abstract}

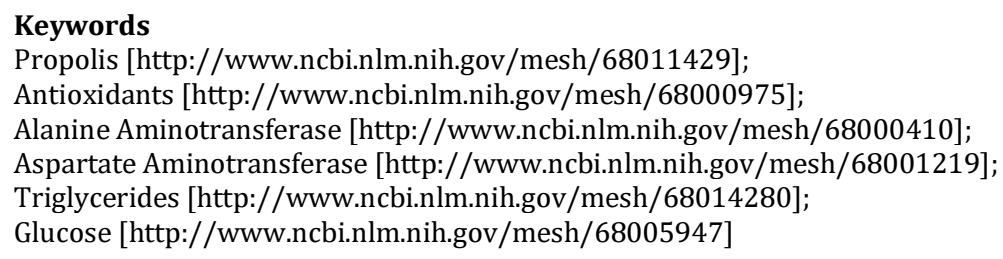

* Corresponding Author

Tel: +982833336001

Fax: +982833324970

Address: Physiology Department, Medicine Faculty, Qazvin University of Medical Sciences, Shahid Bahonar Boulevard, Qazvin, Iran. Postal Code: 3419759811

mohasofi@yahoo.com

Received: May 31, $2015 \quad$ Accepted: January 2, $2016 \quad$ ePublished: March 5, 2016 
(F) أنعمتاله غيبى و همكاران

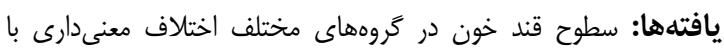

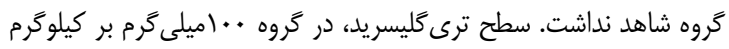

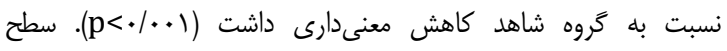

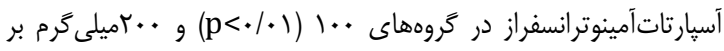

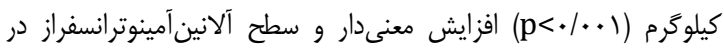

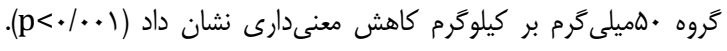

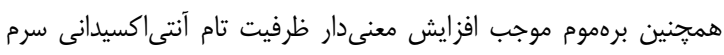

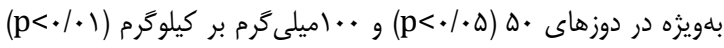

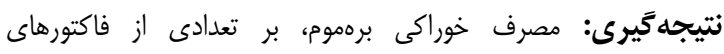

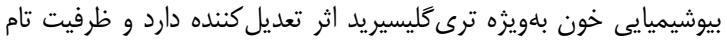

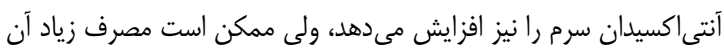

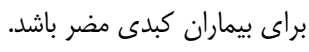

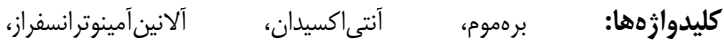
آسبار تاتآمينوترانسفراز، ترى كليسريد، قند

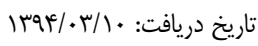

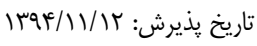

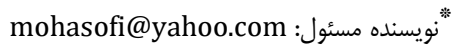

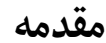

برهموم (يرويوليس) يكى از مهمترين فرآوردههاى طبيعى مشتق از

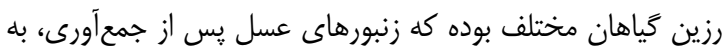

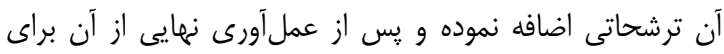

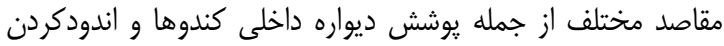

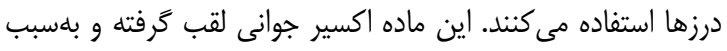
كثرت وجود مواد انرزىزا و بروتئين فراوان، مادهاى بسيار مقوى

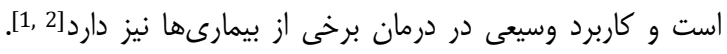

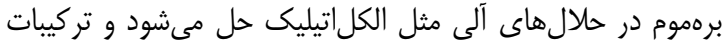

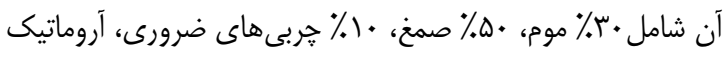

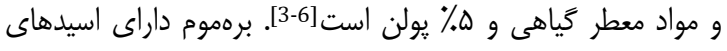

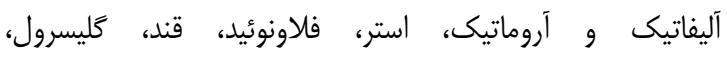
اسيدفسفريك، وانيلين، ميريستين، ويتامينهاى تيامين، ريبوفلاوين،

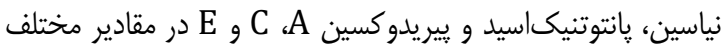

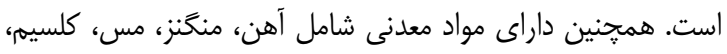

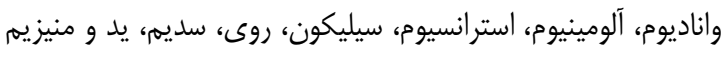

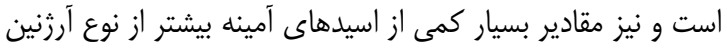

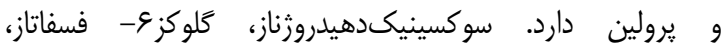

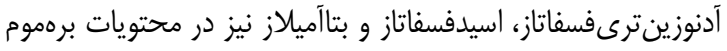

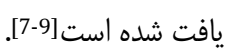

در جند دهه اخير تحقيقات زيادى در مورد خواص درمانى و دارويى إنى

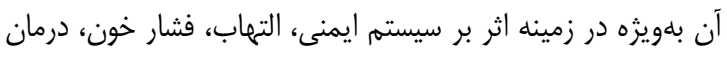
سوختىىها، بيمارىهاى يوستى و سرطان انجام كرفته كه نتايج
اثر عصاره اتانولى برهموم بران سطح سران سرى

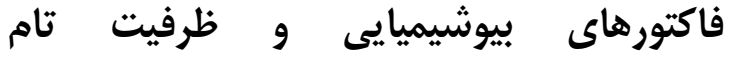
آنتى اكسيدانى در موشهاى صحر ايیى نر بالغ

نعمتاله غيبى PhD

كروه بيوتكنولوزى، دانشكده يِيرايزشكى، دانشكاه علوم يزشكى قزوين، قزوين، ايران

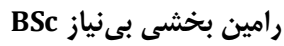

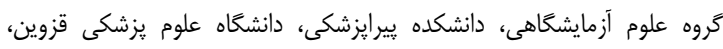
قزوين، ايران

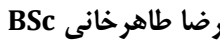
كروه علوم آزمايشَاهى، دانشكده يبيرايزشكى، دانشخاه علوم يزشكى قزوين، قزوين، ايران

حسن جهانى هاشمى PhD

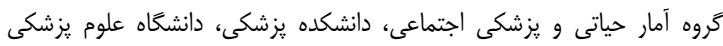
قزوين، قزوين، ايران

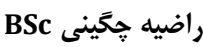
كروه اطاق عمل، دانشكده يِيرايزشكى، دانشكاه علوم يزشكى قزوين، قزوين، ايران

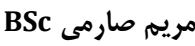
كروه اطاق عمل، دانشكده يبيرايزشكى، دانشكاه علوم يزشكى قزوين، قزوين، ايران

حسن اززدى زرمهرى

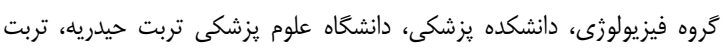
حيدريه، ايران

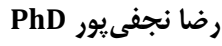
كروه بيوشيمى و زنتيك، دانشكده يزشكى، دانشكاه علوم يزشكى قزوين، قزوين، ايران

PhD محمد صوفى آبادى

كروه فيزيولوزى، دانشكده يزشكى، دانشگاه علوم يزشكى قزوين، قزوين، ايران

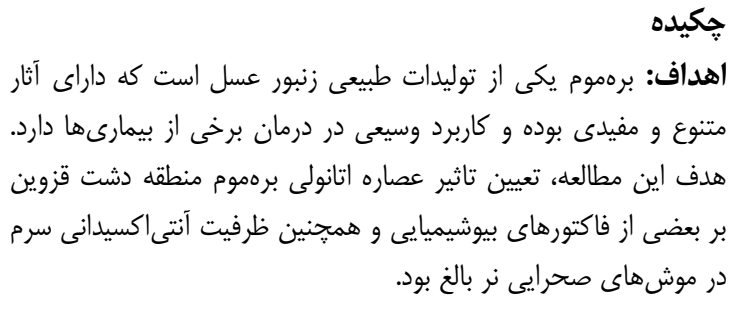

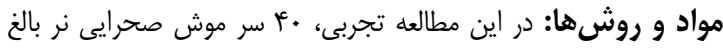

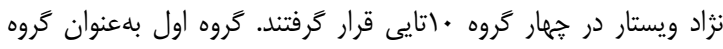

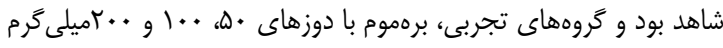

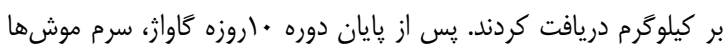

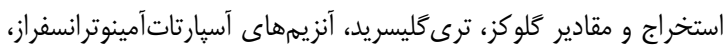

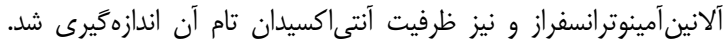

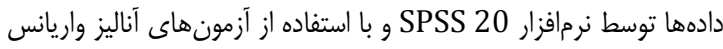
يكىطرفه و يس آزمون توكى مورد تحليل قرار گرفتند. 


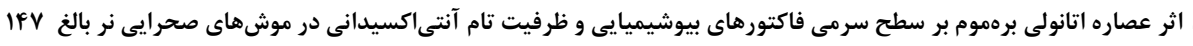

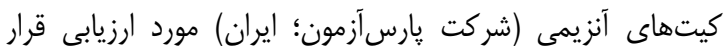

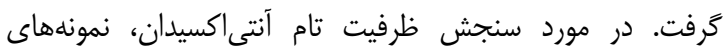

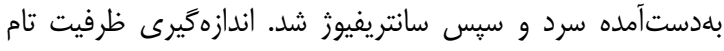
آنتىاكسيدان سرم با استفاده از روش FRAP (قدرت أنتىاكسيدانى احياى آهن) انجام كرفت (شركت سيخما؛ ايالات متحده).

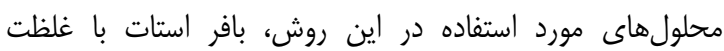

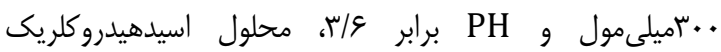

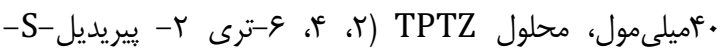

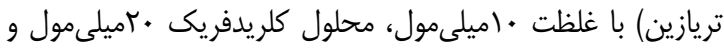

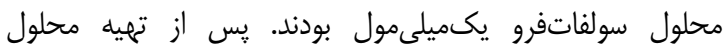

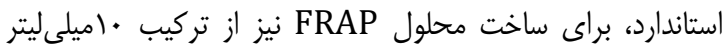

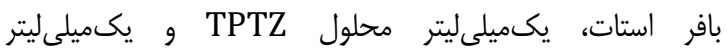

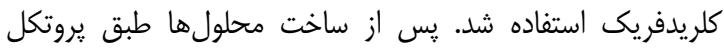

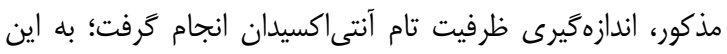

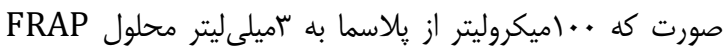

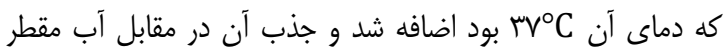

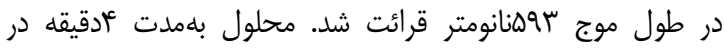

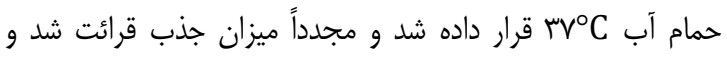

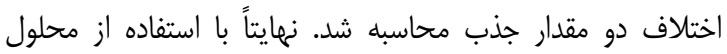

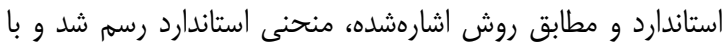
استفاده از آن، مقدار ظرفيت تام آنتىاكسيدانى در نمونههاى مورد الندان

آزمايش، محاسبه شد [21]. اطلاعات حاصله، توسط نرمافزار آمارى 20 SPSS و با استفاده از

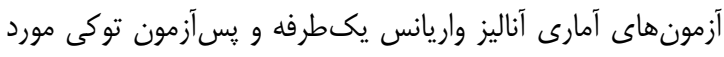

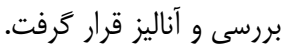

يافتهها

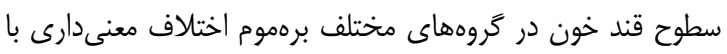

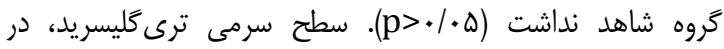

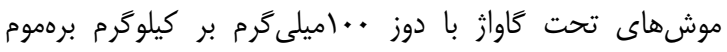

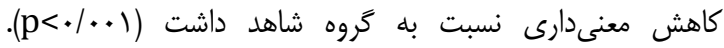

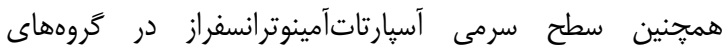

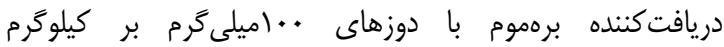

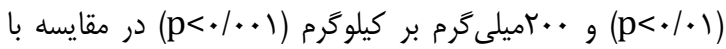

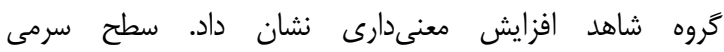

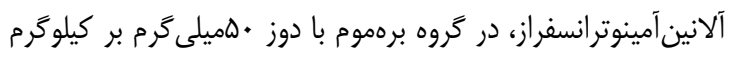

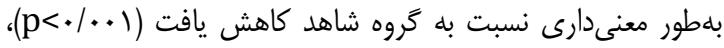

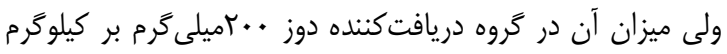

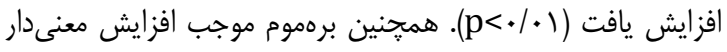

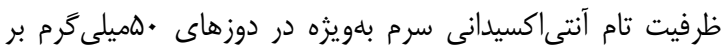

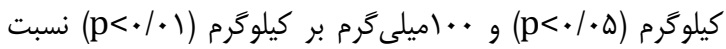

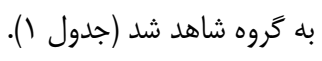

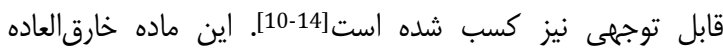

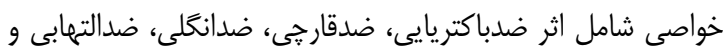

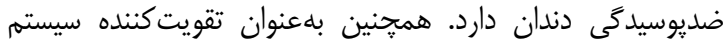

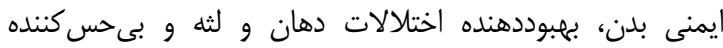

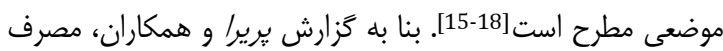

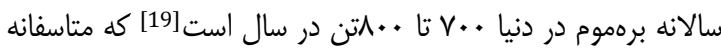

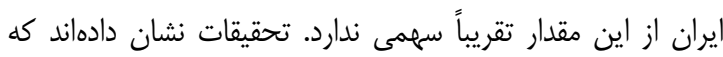

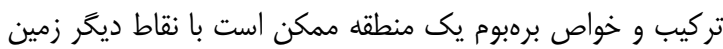
متفاوت باشد [19, 20.

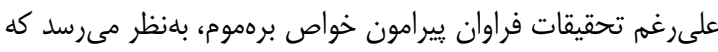

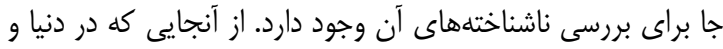

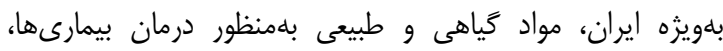

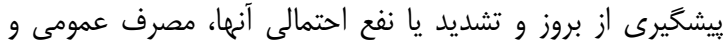

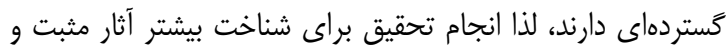
منفى بيوشيميايى آنها ارزشمند است.

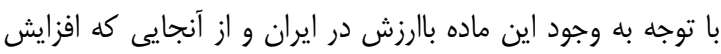

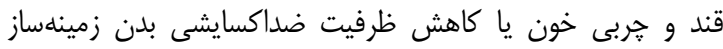

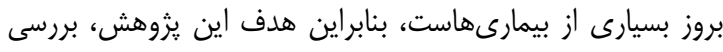

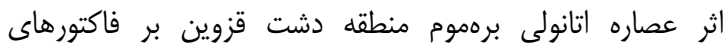

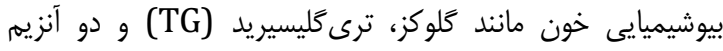
آسيارتاتآمينوترانسفراز (AST) و آلانينآمينوترانسفراز (ALT) و

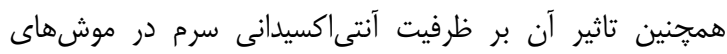

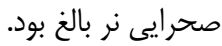

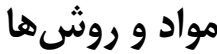

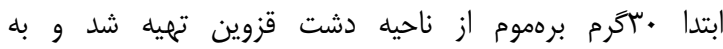

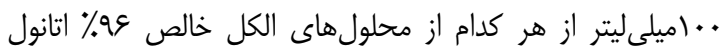

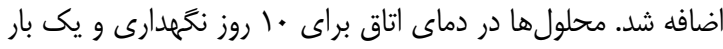

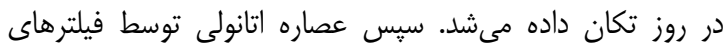

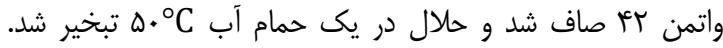

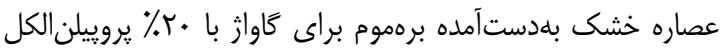

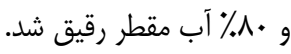

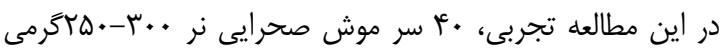

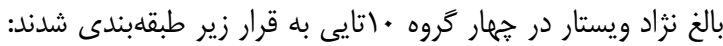

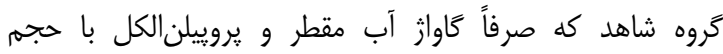

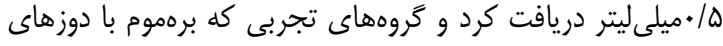

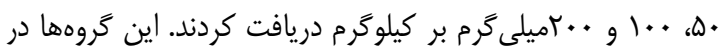

دوره • اروزه بهصورت يك روز در ميان تحت كاواز قرار كر فرتند.

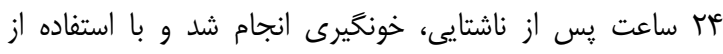

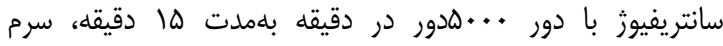

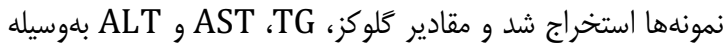




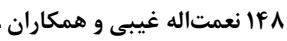

جدول () ميانخين آمارى مقادير فاكتورهاى بيوشيميايى و ظرفيت تام آنتى اكسيدان سرم در موشهاى دريافت كننده دوزهاى مختلف برهموم

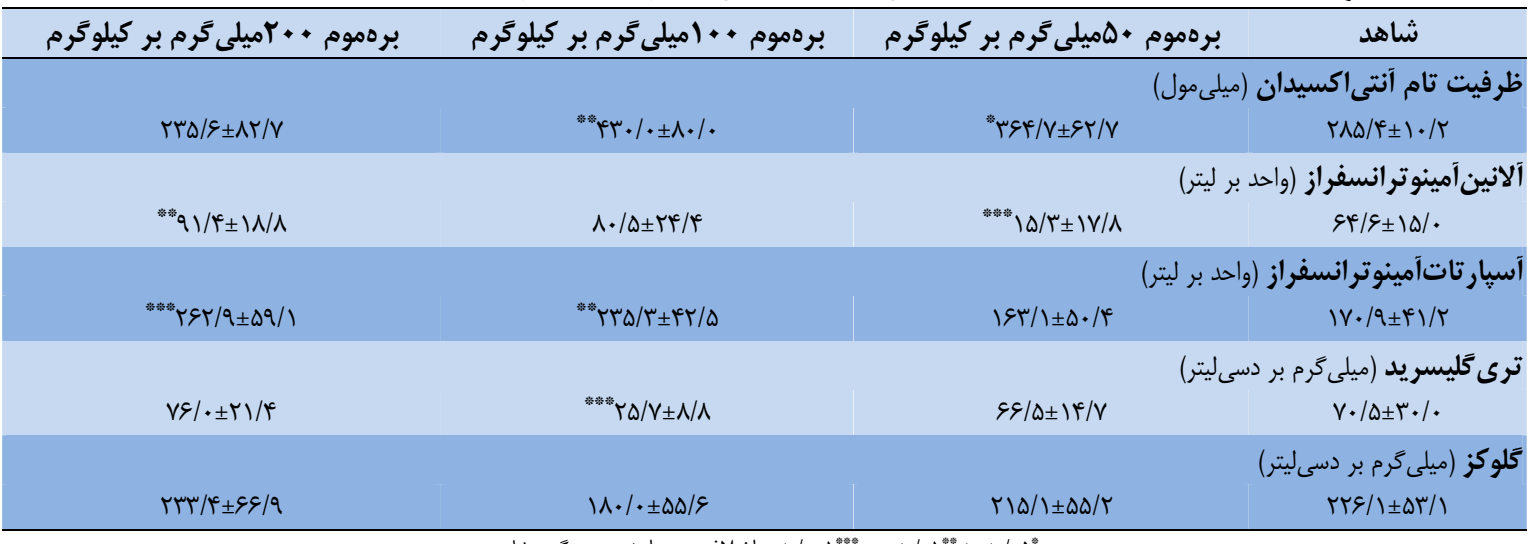

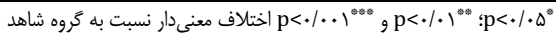

در موشهاى صحرايى تحت مسموميت با آلومينيومكلرايد بررسى

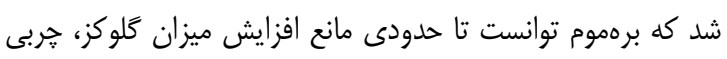

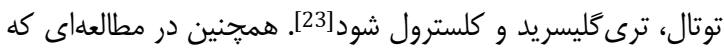

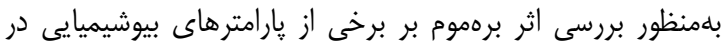

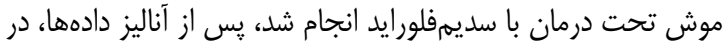

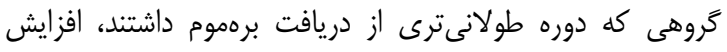

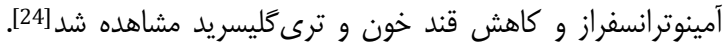

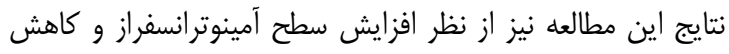

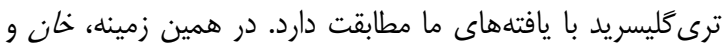

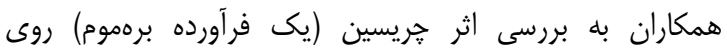

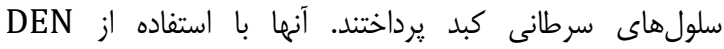

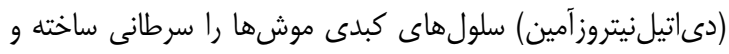

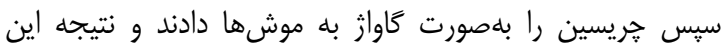

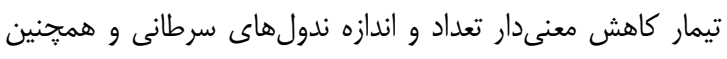

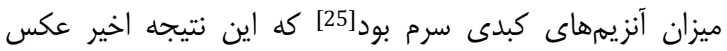

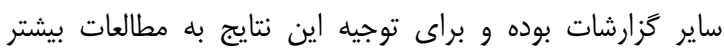

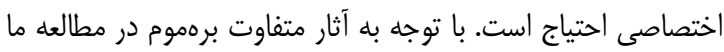

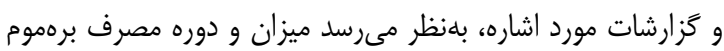

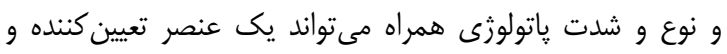

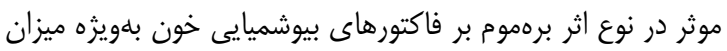

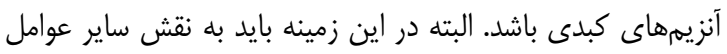

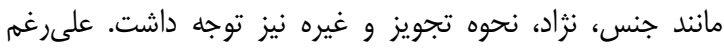

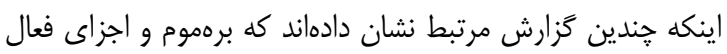

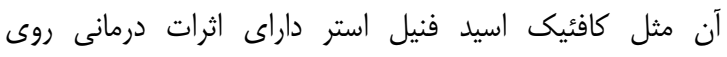

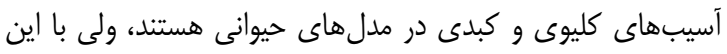

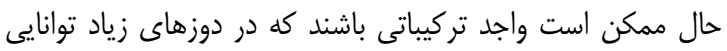

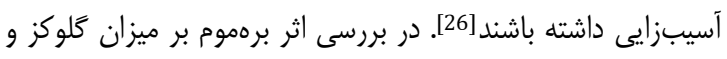

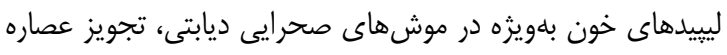

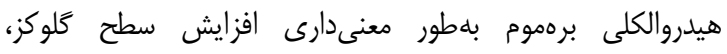
كلسترول و ترى كليسريد ناشى از ديابت را مهار نمود كه احتمالاً
در مطالعه ما، اثر برهموم بر نمايه سرمى برخى از فاكتورهاى

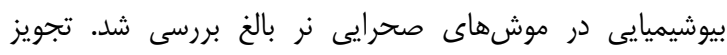

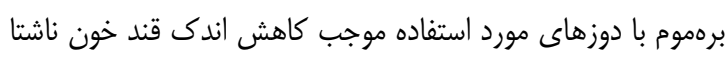

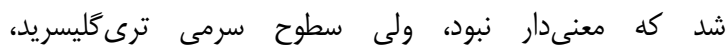

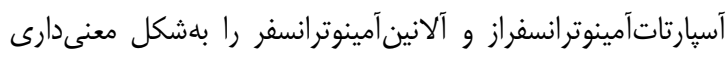

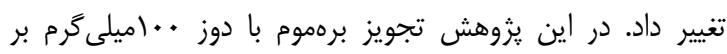

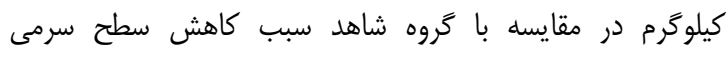

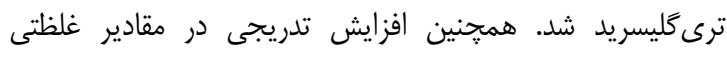

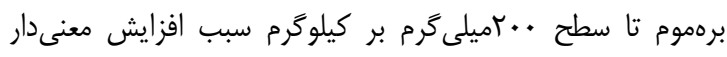

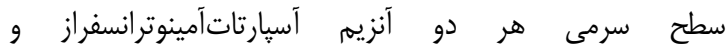

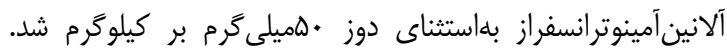

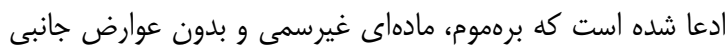

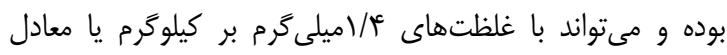

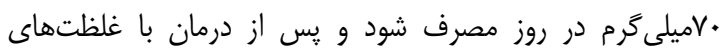

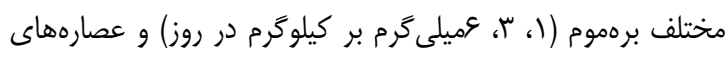

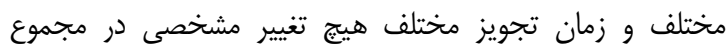

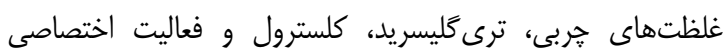
AST و ALT ايجاد نمى كند [22]. در مورد اثر مصرف برهموم بر يارامترهاى بيوشيميايى سرم اطلاعات

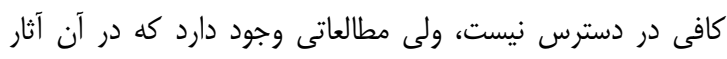

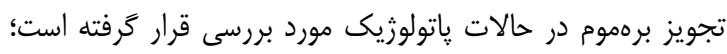

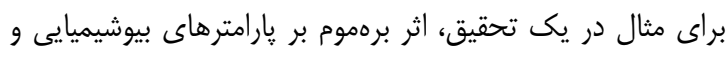

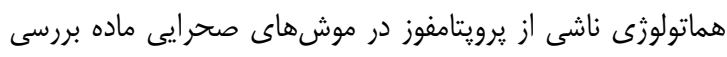

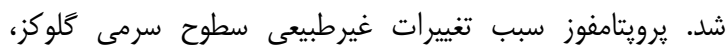

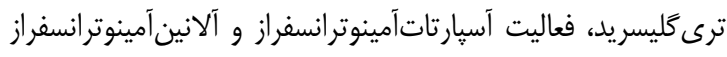

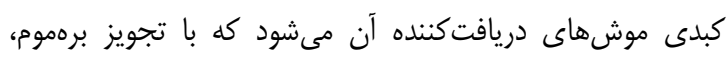

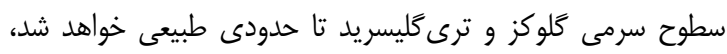

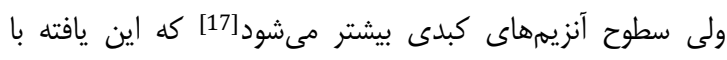

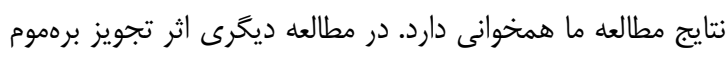

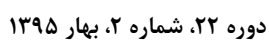

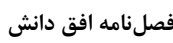




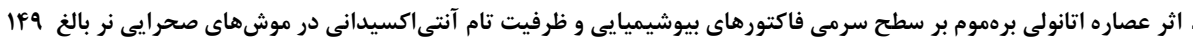

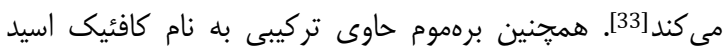

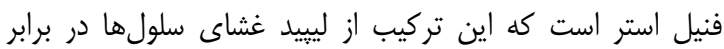

$$
\text { يراكسيداسيون محافظت مى كند [34]. }
$$

محدوديت قابل ذكرى در اين مطالعه وجود نداشت. البته برهبوم

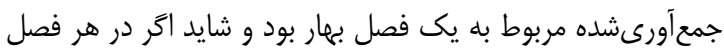

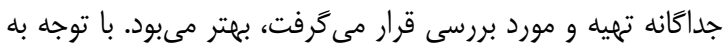

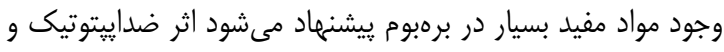
ضدسرطانى ثرويوليس هر منطقه جغرافيايى مورد بررسى قرار گيرد.

\section{نتيجلكيرى}

مصرف خوراكى عصاره اتانولى برهموم منطقه دشت قزوين، بر

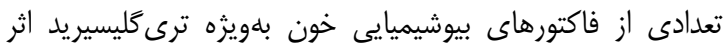

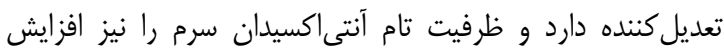
مىدهد، ولى ممكن است مصرف زياد آن براى بيماران كبدى مضر لتر باشد.

تشكر و قدردانى: از مركز رشد و فناورى زيستيزشكى و وإن

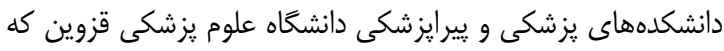

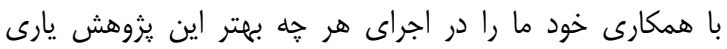
نمودند، قدردانى مىنماييه. تاييديه اخلاقى: انجام اين :ثروهش توسط كميته اخلاق دانشگاه علوم يزشكى قزوين مورد تاييد قرار گرفته است. تعارض منافع: هيج گونه تعارض منافع توسط نويسندگان بيان

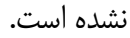
منابع مالى: اين مقاله حاصل طرح يثوهشى مركز رشد و فناورى

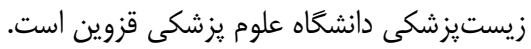

منابع

1- Bankova V, Popova M, Trusheva B. Propolis volatile compounds: chemical diversity and biological activity: A review. Chem Cent J. 2014; 8:28-36.

2- Koya-Miyata S, Arai N, Mizote A, Taniguchi Y, Ushio S, Iwaki $\mathrm{K}$, et al. Propolis prevents diet-induced hyperlipidemia and mitigates weight gain in dietinduced obesity in mice. Biol Pharm Bull. 2009;32(12):2022-8.

3- Calderón-Montaño JM, Burgos-Morón E, PérezGuerrero C, López-Lázaro M. A review on the dietary flavonoid kaempferol. Mini Rev Med Chem. 2011;11(4):298-344.

4- Sforcin JM, Bankova V. Propolis: is there a potential for the development of new drugs?. J Ethnopharmacol. 2011;133(2):253-60.

5- Burdock GA. Review of the biological properties and toxicity of bee propolis. Food Chem Toxicol. 1998;36(4):347-63.

6- Scifo C, Cardile V, Russo A, Consoli R, Vancheri C, Capasso $\mathrm{F}$, et al. Resveratrol and propolis as necrosis or apoptosis inducers in human prostate carcinoma cells. Oncol Res. 2004;14(9):415-26.
بخشى از اين اثرات مىتواند ناشى از تركيبات فلاونوئئيدى،

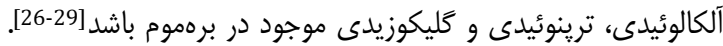

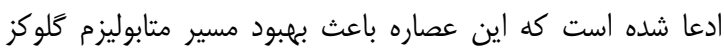

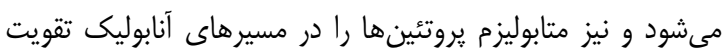

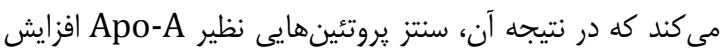

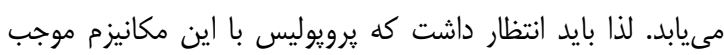

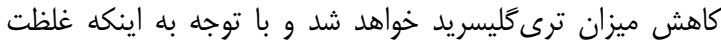
HDL

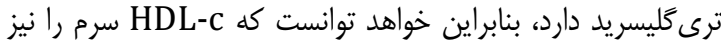

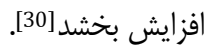

در مطالعه ما علاوه بر يارامترهاى بيوشيميايى، اثر برهموم بر ظرفيت

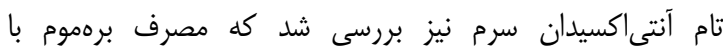

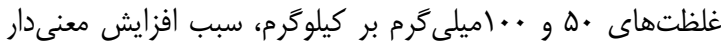
ظرفيت تام آنتىاكسيدان سرم نسبت به كَروه شاهد شد. در تحقيق

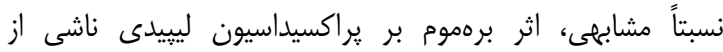

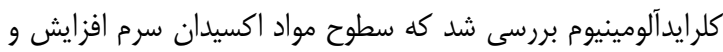

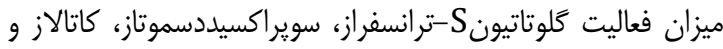

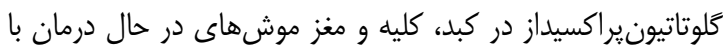
كلرايدآلومينيوم كاهش يافت، ولى در موشهائي كه با با برهموم هم تيمار شدند سطح اكسيدانهاى سرم كاهش و ميزان آنزيمهائ

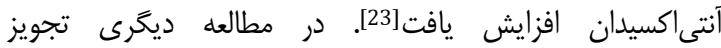
سديمفلورايد به موش موجب كاهش سطح آنتىاكسيدان سرم شد،

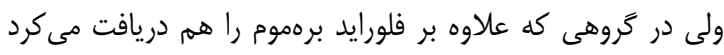

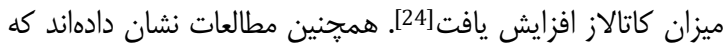

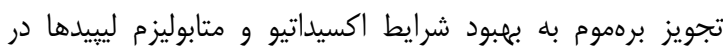

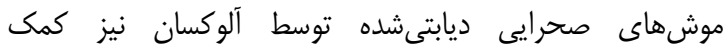

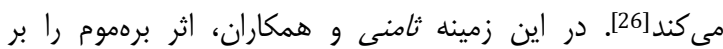

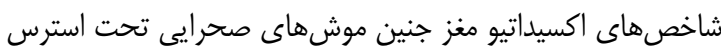
بررسى كردند و نشان دادند كه برهموم قادر است از از كاهش

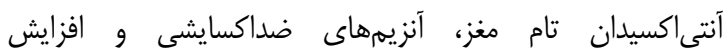

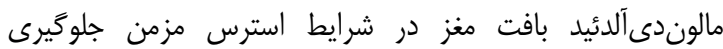

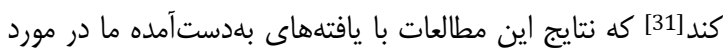

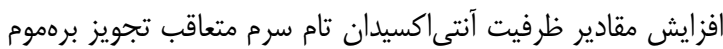
همخوانى دارد.

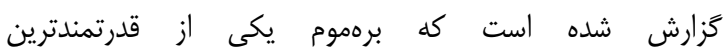

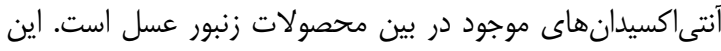

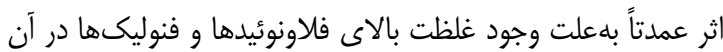

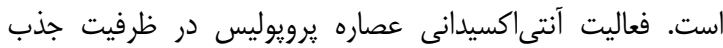

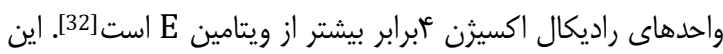
تركيبات قادر به برداشت راديكالهاى آزاد، حفاظت ليييدها و ديكر آنيخر

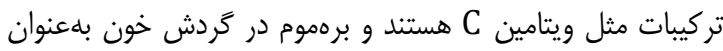
يك آنتى|كسيدان آبدوست به جذب ويتامين C هم كمى كن 
21- Benzie IF, Strain JJ. The ferric reducing ability of plasma (FRAP) as a measure of "antioxidant power": the FRAP assay. Anal Biochem. 1996;239(1):70-6.

22- Fernandes FF, Dias AL, Ramos CL, Ikegaki M, de Siqueira AM, Franco MC. The "in vitro" antifungal activity evaluation of propolis G12 ethanol extract on Cryptococcus neoformans. J Rev Inst Med Trop Sao Paulo. 2007;49(2):93-5.

23- Newairy AS, Salama AF, Hussien HM, Yousef MI. Propolis alleviates aluminium-induced lipid peroxidation and biochemical parameters in male rats. Food Chem Toxicol. 2009;47(6):1093-8.

24- Eraslan G, Kanbur M, Silici S. Evaluation of propolis evicts on some biochemical parameters in rats treated with sodium Fluoride. Pestic Biochem Physiology. 2007;88(3):273-83.

25- Khan MS, Devaraj H, Devaraj N. Chrysin abrogates early hepatocarcinogenesis and induces apoptosis in $\mathrm{N}$ nitrosodiethylamine-induced preneoplastic nodules in rats. Toxicol Appl Pharmacol. 2011;251(1):85-94.

26- Zhu W, Chen M, Shou Q, Li Y, Hu F. Biological activities of chinese propolis and brazilian propolis on streptozotocine induced type 1 diabetes mellitus in rats. Evid Based Complement Altern Med. 2011;2011:468529. 27- Sameni H, Ramhormozi P, Bandegi A, Taherian A, Safari M, Tabriziamjad M. Effects of hydroalcoholic extract of Iranian Propolis on blood serum biochemical factors in streptozotocin-induced diabetic rats. Koomesh. 2014;15(3):388-95. [Persian]

28- Vaya J, Aviram M. Nutritional antioxidants: Mechanism of action, analyses of activities and medical applications. Curr Med Chem Immun End Metab Age. 2001;1(1):99-117.

29- Lukačínová A, Mojžiš J, Beňačka R, Keller J, Maguth T, Kurila $\mathrm{P}$, et al. Preventive Effects of Flavonoids on Alloxan-Induced Diabetes Mellitus in Rats. Acta Vet Brno. 2008;77:175-82.

30- Abo-Salem OM, El-Edel RH, Harisa GE, El-Halawany $\mathrm{N}$, Ghonaim MM. Experimental diabetic nephropathy can be prevented by propolis: effect on metabolic disturbances and renal oxidative parameters. Pak J Pharm Sci. 2009;22(2):205-10.

31-Sameni H, Kavakebian F, Tabriziamjad M, Bandegi A, Yousefi B, Taherian A. Effects of hydroalcoholic extract of Propolis on oxidative stress indices of rat fetal brain induced by chronic prenatal stress. Koomesh. 2014;15(4):482-92. [Persian]

32- Sheng J, Zhou J, Wang L, Xu J, Hu Q. Antioxidant activity of ethanol and petroleum ether extracts from Brazilian propolis. Eurn Food Res Technol. 2007;225:249-53.

33- El-Masry TA, Emara AM, El-Shitany NA. Possible protective effect of propolis against lead induced neurotoxicity in animal model. J Evolut Biol Res. 2011;3(1):4-11.

34- Seven I, Aksu T, Seven PT. The effects of propolis on biochemical parameters and activity of antioxidant enzymes in broilers exposed to lead-induced oxidative stress. Asian Australas J Anim Sci. 2010;23(11):1482-9.
7- De Vecchi E, Drago L. [Propolis' antimicrobial activity: What's new?]. Infez Med. 2007;15(1):7-15. [Italian] 8- Kujumgiev A, Tsvetkova I, Serkedjieva Y, Bankova V, Christov R, Popov S. Antibacterial, antifungal and antiviral activity of propolis of different geographic origin. J Ethnopharmacol.1999;64(3):235-40

9- de Figueiredo SM, Nogueira-Machado JA, Almeida Bde M, Abreu SR, de Abreu JA, Filho SA, et al. Immunomodulatory properties of green propolis. Recent Pat Endocr Metab Immune Drug Discov. 2014;8(2):85-94. 10- Shimizu T, Takeshita Y, Takamori Y, Kai H, Sawamura $\mathrm{R}$, Yoshida $\mathrm{H}$, et al. Efficacy of Brazilian propolis against Herpes Simplex virus type 1 infection in mice and their modes of antiherpetic efficacies. Evid Based Complement Alternat Med. 2011;14:96-104.

11- Premratanachai P, Chanchao C. Review of the anticancer activities of bee products. Asian Pac J Trop Biomed. 2014;4(5):337-44.

12- Murad JM, Calvi SA, Soares, Bankova V, Sforcin JM. Effect of propolis from Brazil and Bulgari on fungucidal activity of macrophage against Paracoccidioides brasiliensis. J Ethnopharm. 2002;79(3):331-4.

13- Feres M, Figueiredo LC, Barreto IM, Coelho $\mathrm{MH}_{\text {, }}$ Araujo MW, Cortelli SC. In vitro antimicrobial activity of plant extracts and propolis in saliva samples of healthy and periodontally- involved subjects. J Int Acad Periodontol. 2005;7(3):90-6.

14- Ownagh A, Tukmechi A, Adibhesam M, Ebrahimzadeh S. Comparison study on the effect of ethanol extract of propolis collected from west Azerbaijan against dermatophytes fungi. Urmia Med J. 2010;21(3):206-14.

15- Momen Beitollahi J, Mansorian A, Esmaili M, Amanlou M, Mohamadnia A, Bahrami N. Antimicrobial effects of propolis extract on the most prevalent oral pathogens: An in vitro study. Majallah-i-dandanpizishki. 2009;21(1):33-9. [Persian]

16- Fereidooni M, Khosravi Samani M, Amiri A, Seyed M, Haji Ahmadi M. Comparison of the effect of propolis and traditional toothpaste on bacterial plaque. J Babol Univ Med Sci. 2014;16(2):17-22. [Persian]

17- Velikova M, Bankova V, Tsvetkova I, Kujumgiev A, Marcucci MC. Antibacterial ent-kaurene from Brazilian propolis of native stingless bees. Fitotrapia. 2000;71(6):690-3.

18- Danert FC, Zampini C, Ordoñez R, Maldonado L, Bedascarrasbure E, Isla MI. Nutritional and functional properties of aqueous and hydroalcoholic extracts from Argentinean propolis. Nat Prod Commun 2014;9(2):167-70.

19- Guo X, Chen B, Luo L, Zhang X, Dai X, Gong S. Chemical compositions and antioxidant activities of water extracts of Chinese propolis. J Agric Food Chem. 2011;59(23):12610-6.

20- Afrouzan H, Tahmasebi Gh, Bankova V, Bigdeli M. Comparison of quantity and quality of propolis produced by gymnosperms and angiosperms plants in northeast of Tehran, Iran. Pajouhesh Sazandegi .2008;77:155-62. [Persian] 